\title{
Imaging in Gluteal Hernia
}

\author{
Chaitra Srinivas, Ajit Kumar Reddy, Anil Kumar Shukla, Himabindhu Pinnammaneni \\ Department of Radiodiagnosis, Kempegowda Institute of Medical Sciences, Bangalore, India \\ Email: chaitra612@gmail.com,drajitreddy@gmail.com,shookla2007@yahoo.co.in, \\ drbindupinnamaneni@gmail.com
}

Received 11 December 2015; accepted 15 March 2016; published 18 March 2016

Copyright (C) 2016 by authors and Scientific Research Publishing Inc.

This work is licensed under the Creative Commons Attribution International License (CC BY). http://creativecommons.org/licenses/by/4.0/

(c) (i) Open Access

\begin{abstract}
Gluteal hernias are extremely uncommon and occur as a result of deficiency or defect in the gluteal musculature. Our case reports one such incidence in a one year old girl with review of available literature. The clinical presentation and imaging findings are discussed comprehensively. We thus lay emphasis on the importance of real-time ultrasonography as the method of choice to identify hernia contents, peristalsis and obstruction if any.
\end{abstract}

\section{Keywords}

\section{Gluteal, Hernia, Defect, Sonography, Obstruction}

\section{Introduction}

Gluteal hernia is a rare type of hernia that results from weakness or deficiency of the gluteal muscle fibres. It may be due to defect in levator ani or arise between the levator ani and coccygeus muscles. Congenital weaknesses or openings in the musculature of the lower back with associated anomalous bony development specially predispose to such hernias. Perineal hernias may be anterior or posterior depending on their position with respect to the transverse perineii muscle. The treatment of such hernias is often surgical, as in this case, an accurate preoperative evaluation is mandatory as the complications may be dire. In this report, we present our experience in the diagnosis and treatment of gluteal hernia in a one year old girl with a review of relevant literature.

\section{Case Description}

A one year old female child presented to the outpatient department with a painless reducible mass in the left buttock along the superio-lateral aspect. Grossly the lump appeared pale at the base and slightly discolored at the apex. The parents noticed the swelling at birth which increased in size over the year. Transient increase in size of swelling was seen when the child strained or cried. Bowel habits of the child remained normal.

On inspection asymmetry of the gluteal region was noted with the affected side showing relative atrophy of 
the gluteal musculature. The mass was soft palpable and reduced on compression. Bowel sounds were heard at the site of swelling on auscultation.

The child was then subjected to X-ray and sonography. Plain X-ray radiographs (Figure 1) of the child's pelvis revealed a soft tissue opacity along the superio-lateral aspect of left gluteal region with associated agenesis of theileo-sacral bone.

On sonographic evaluation heterogeneously echoic areas with reverberating shadows was seen in the region of the palpable mass, suggestive of bowel loops. Relative atrophy of the left gluteal musculature with inferolateral herniation of bowel loops through a defect was seen (Figures 2-4). There was no sign of strangulation seen.

Through a posterior approach the hernia sac was reduced and reinforced with synthetic prosthesis. Sacral reconstruction was postponed to child bearing age.

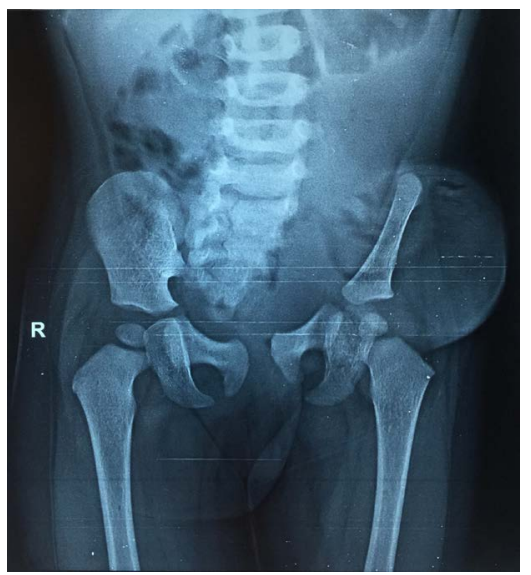

Figure 1. X-ray radiograph AP view of the pelvis showing left ilio-sacral agenesis with a left lateral soft tissue.

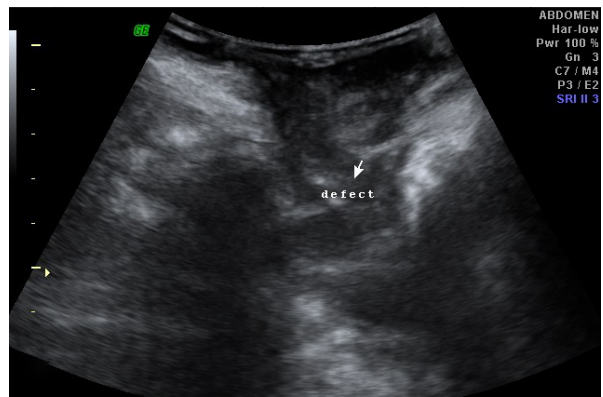

Figure 2. Ultrasonogram transverse view at the base of swelling demonstrating the defect (arrow).

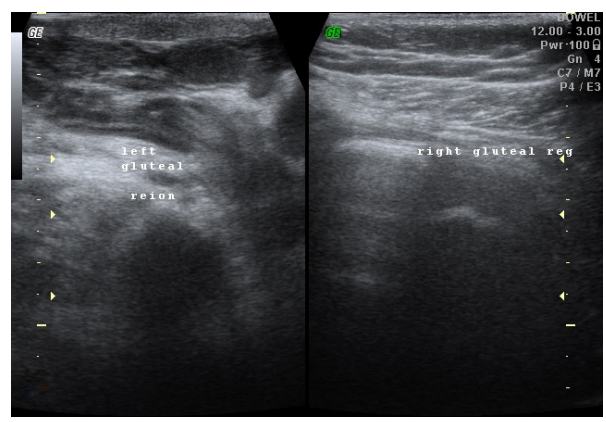

Figure 3. Ultrasonogram transverse view depicting a comparison of both gluteal regions. Relative atrophy of left gluteal musculature noted. 


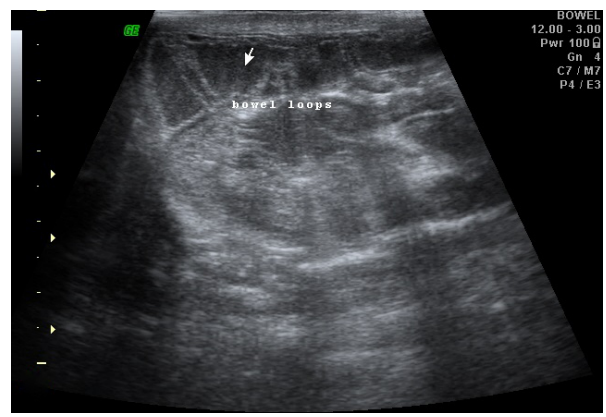

Figure 4. Ultrasonogram at the site of swelling showing bowel loops herniating through the above shown defect.

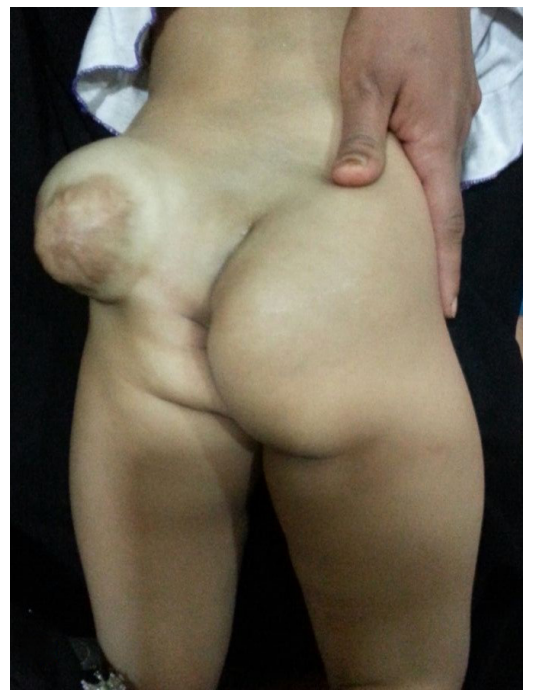

Figure 5. Clinical picture demonstrating the soft palpable mass in the left gluteal region.

\section{Discussion}

By far, the most common hernias (up to $75 \%$ of all abdominal hernias) are the inguinal hernias. Most hernias present with a palpable/visible lump which may or may not be symptomatic. Patients commonly present with bowel obstruction, strangulation or organ dysfunction. Fatty tissue is the most common content of a hernia followed by bowel loops and organ. Through a posterior approach the hernia sac (Figure 5) was reduced and reinforced with synthetic prosthesis. Sacral re-construction was postponed to child bearing age.

Pelvic hernias are very rare and mainly of three types most common being obturator followed by perineal and sciatic. Gluteal hernia of this variety is very uncommon. Perineal hernias may be primary (congenital or acquired) or secondary tore constructed pelvic floor incisions. Sciatic hernia in the greater sciatic foramen occasionally presents as an uncomfortable mass in the gluteal region. Bowel obstruction may also occur and rarely cause sciatic neuralgia.

Some of the predisposing factors include chronic obstructive pulmonary disease, obesity, pregnancy and previous surgeries [1].

First described by Papen in 1750 and observed and recorded by Verdier in 1753, articles in the literature concerning this pelvic floor hernia are few. Roughly 35 cases have been documented till date by Watson et al. since 1750 [2]-[10].

Primary forms are extremely rare; in pediatric population they are even rarer. Of the 100 cases that have been reported in the literature, only about 6 cases are reported in children.

Treatment option includes muscle reinforcement techniques with the aid of synthetic prosthesis [11]. In our case, as the patient is very young, regular follow-up may be required followed by sacral reconstruction at child 
bearing age.

\section{Funding}

None.

\section{Consent}

A written consent was taken from the child's parents.

\section{References}

[1] Kravarusic, D., Freud, E. and Swartz, M. (2012) Perineal Hernias in Children: Case Report and Review of the Literature. African Journal of Paediatric Surgery, 9,172. http://dx.doi.org/10.4103/0189-6725.99411

[2] Watson, L.F. (1948) Hernia: Anatomy, Etiology, Symptoms Diagnosis, Differential Diagnosis, Prognosis and Treatment. 3rd Edition, Mosby, St. Louis.

[3] Sadek, H.M., Kiss, D.R. and Vanconcelos, E. (1970) Sciatic Hernia Caused by a Neurofibroma. Surgical Repair with Stainless Steel Wire Mesh. International Surgery, 54, 135-141.

[4] Lindbom, A. (1947) Unusual Ureteral Obstruction by Herniation of Ureter into Sciatic Foramen: Report of a Case. Acta Radiologica, 28, 225-226.

[5] Beck, W.C., Baurys, W., Brochu, J. and Morton, W.A. (1952) Herniation of the Ureter into the Sciatic Foramen. JAMA, 149, 441-442. http://dx.doi.org/10.1001/jama.1952.72930220001010

[6] Henegar, G.C. (1952) Sciatic Notch Hernia: Report of a Case and Description of a New Operative Approach. Archives of Surgery, 64, 399-400. http://dx.doi.org/10.1001/archsurg.1952.01260010413016

[7] Gaffney, L.B. and Schanno, J.P. (1958) Sciatic Hernia: A Case of Congenital Occurrence. The American Journal of Surgery, 95, 974-975. http://dx.doi.org/10.1016/0002-9610(58)90843-2

[8] Franken Jr., B.A. and Smith, E.E. (1969) Sciatic Hernia: Report of Three Cases Including Two with Bilateral Ureteral Involvement. The American Journal of Roentgenology, Radium Therapy, and Nuclear Medicine, 107, 791-795.

[9] Brodnax, J.W. (1924) Sciatic Hernia: Report of a Case of Herniation of Meckel's Diverticulum through the Greater Sciatic Foramen. JAMA, 82, 440-442. http://dx.doi.org/10.1001/jama.1924.02650320010004

[10] Wikipedia (2015) Hernia. http://en.wikipedia.org/wiki/Hernia

[11] Miklos, J. (1998) Sciatic Hernia as a Cause of Chronic Pelvic Pain in Women. Obstetrics \& Gynecology, 91, 998-1001. http://dx.doi.org/10.1016/S0029-7844(98)00085-4 